\title{
Deontology to Judge the Ethical Business Actions: The Case of Takata
}

\author{
Yunluan Chen \\ Monash Business School, Monash University, Melbourne, Australia \\ Email: yunluanchen@gmail.com
}

How to cite this paper: Chen, Y.L. (2019) Deontology to Judge the Ethical Business Actions: The Case of Takata. Open Journal of Business and Management, 7, 783-787. https://doi.org/10.4236/ojbm.2019.72052

Received: March 22, 2019

Accepted: April 9, 2019

Published: April 12, 2019

Copyright $\odot 2019$ by author(s) and Scientific Research Publishing Inc. This work is licensed under the Creative Commons Attribution International License (CC BY 4.0).

http://creativecommons.org/licenses/by/4.0/

\begin{abstract}
Business ethics is crucial to corporates' subsistence and development. Many corporates have considered ethical factors on their operation strategies. This paper is to judge Takata actions in the exploding airbags events whether ethical or not by Deontology as the ethical theory. Takata's actions are analyzed mainly whether these conform to three principles of the Categorical Imperatives and detail their business operating issues. We conclude that Takata's actions are not ethical since they isolate theories of duty. In order to operate ethically, corporations could design a better reporting system in the specific industry and reinforce the responsible law to be held responsible to individuals.
\end{abstract}

\section{Keywords}

Deontology, Business Ethics, Takata

\section{Introduction}

The purpose of this paper is to identify the fraud of Takata in the exploding airbags events and make a judgement on whether their actions are ethical or not. The findings indicate that companies should operate ethically and be responsible for their own actions. In this paper, there are five sections. Firstly, the background of Takata airbags event is introduced briefly and the research issues that whether Takata's actions are ethical and to what extent Takata should be blamed will be pointed out. Secondly, this paper summarises Deontology as the applied ethical theory and Kant's opinions on ethics of duty and explains three principles of the Categorical Imperatives. Then, the paper builds on the analyses of the above specific issues by theories of duty, the Categorical Imperatives and concludes that the actions of Takata are not ethical. Furthermore, this paper provides the implications for business practice. On the one hand, employees in companies should positively report bad actions. On the other hand, relevant de- 
partments could set up a better reporting system and reinforce laws about investigating and affixing the personal responsibility for bad actions. In conclusion, Takata should be responsible for their unethical actions and be blamed largely in this event. In addition, companies could use proposed recommendations to standardise their behaviours to be ethical.

\section{Background}

Takata was a Japanese auto parts supplier and one of the largest auto airbag manufacturers in the world. However, their airbag has defect and is not safe. In fact, there were a few complaints about safety issues of Takata airbags in 2000, but they were ignored [1]. In addition, Takata considered that airbags exploding apparently was not a widespread problem in 2004 [2]. Then, the recall of vehicles linked with defect airbags was started in 2008 in the United States of America. Moreover, the events of Takata airbag fatalities has been revealed constantly and focused on by National Highway Traffic Safety Administration since 2009. Up to now, there are at least 16 deaths and 180 injuries due to Takata airbags bombing and it has resulted in more than 40 million vehicles recall between dozens of vehicle brands which was the largest auto recall in history [3]. On May 18, 2015, Takata admitted that there were security risks in their airbag but refused to release the problem detail about airbag defect. Nevertheless, according to investigations, Takata was indicated that it had controlled data of inflators' testing, removed bad data and provided inaccurate data to regulators [4]. On February 27, 2017, Takata pleaded guilty in an American court to fraud and would pay 1 billion dollars settlement which could be as compensation to auto brands and victims of Takata airbags event [3]. Takata has been heavily in debt. On June 26, 2017, a bankruptcy petition for Takata was filed [5]. Furthermore, some brands and governments continue recalling autos with Takata airbags in the world. Takata is still a representative of danger in auto industry to this day.

In summary, this case is described mainly around actions of Takata. The case includes Takata and its stakeholders and has been happening for a long time. According to this case, the paper addresses the following two significant issues. Are the actions of Takata ethical? Should Takata be largely to blame for the airbag fatalities?

\section{Explanation}

Deontology as the ethical theory will be applied in this paper. Deontology, also called Ethics of Duty, is one of Non-consequentialist theories. It indicates that people must act in compliance with some ethical principles or rules rather than considering consequences whether good or not [6]. Duty plays a significant role in the standard of determining ethical behaviours. For example, when benefits belong to desires and good will is one of standards, if people act only because they can get benefits but not good will, they could not be regarded as ethical. In addition, it is different from other ethical theories on some aspects such as re- 
cognising intent, acting distinction, positive or negative duty, perfect or imperfect and recognition of different degrees of blame and praise.

There are many philosophers who have made their contributions to Deontology, and Immanuel Kant is one of representatives. He proposed rationalistic ethics of duty and claimed ethics are based on not desires, but rational will [7]. Kant also presented the Categorical Imperatives including three principles which can determine what the duty is. Firstly, people should act according to maxim, and also it will become a universal law. Secondly, whoever should not treat anyone only as tools, but consider that they are rational in themselves. Thirdly, all rational actions might be the universal nature law, and people should not only act according to right laws, but also treat themselves freely accepted by each rational being [8]. It also can be said that when one person would like to be treated by a rational way, he should treat others in the same rational way.

\section{Analysis and Evaluation}

The actions of Takata in this case could be identified and evaluated by Deontology. If Takata is considered as being ethical, it should comply with the Categorical Imperatives of Deontology. On the aspect of the "universality" rule, Takata as a supplier needs to provide safe and qualified airbags to auto brands to make vehicles. If each manufacturer produces safe and qualified auto parts, the probability of deaths and injuries due to auto parts will be approximately nil. On the aspect of "human dignity" rule, Takata producing airbags not only is to satisfy its own desire such as making more profits for themselves, but also can ensure other auto brands and customers without loss in auto area. For example, auto brands can sell high quality vehicles and customers can enjoy great vehicle services. In this way, others could accept Takata's actions. On the aspect of "publicity" rule, to produce safe and qualified items must be a standard of production for each company.

However, actually Takata did not act this way. Firstly, Takata was investigated on the fact that it controlled the data test and removed bad data to make reports of products look like qualified [9]. Secondly, Takata described that the defects occurred in the specific event which was not a wide problem, and then tried to announce that they have improved them and ensure safe and quality of products. However, the deaths and injuries still occurred due to defects. In fact, the internal file of Takata indicated engineers have been recording problems about airbags [1]. Thirdly, management of Takata was not aware of the harm of producing poor airbags and agreed it [10]. They might only concentrate to earn benefits from the auto airbag business. As a result, there is the fraud from Takata towards other brands and customers.

The above three aspects of actions violate the Categorical Imperatives. On the one hand, "universality" rule and "publicity" rule are not met. Takata's actions must be not accepted by other brands and customers so it is impossible to become a public standard. On the other hand, "human dignity" rule is not met. 
Takata only thought about its own benefits, and treated others through the fraud which Takata hid the truth of defects. This means they are not honest, and information are often not accurate. This behaviour could damage others' benefits. Therefore, the actions of Takata are not ethical and it should be blamed.

There is another issue about who should be largely to blame for the airbag fatalities. Due to above analysis, Takata's actions are the main reasons resulting the bad event, so it should be largely to blame for the airbag fatalities. In addition, relevant departments and other auto brands such as Honda, Toyota, Nissan, Subaru and Mitsubishi also should be blamed for the event. To some extent, brands are victims because they need to spend extra money and time recalling the decent vehicles by themselves even though Takata compensates some of them [3]. However, these brands and relevant departments also ignored the problems when it just happened in 2000. In 2008, the decent airbag recall has started but there are eight-year differences between this and the first complaint [3]. On these aspects, they might not always use goodwill to be the motivation of solving problems, because if they always used goodwill, these brands and departments would focus on each possible problem and solve them until obtaining reliable safety reports or early recalling.

\section{Implications for Business Practice}

Vadastreanu, Maier and Maier claim that through following business ethics and deontology, people and companies could achieve success [11]. It might mean if Takata complied with Deontology, it would operate successfully rather than going bankrupt. There are several methods for ethical operation of a business. On the one hand, employees who know the bad actions of Takata should be honest and report the true results. This action is ethical because they may tell the truth and not consider these consequences whether good or bad. However, when they tell the truth, the benefit of business might be decreased, and employees might lose their own jobs. In fact, some employees who know the truth do not dare to tell. Thus, relevant departments and industry can set up a better reporting system and the information cannot be taken by managements who earn inappropriate profits [9]. By this means, employees' fame and live can be protected and they will be more positive to reveal bad things. On the other hand, relevant departments could reinforce laws about investigating and affixing the personal responsibility for bad actions of companies. By this way, the strict rule as Categorical Imperatives will be set up, and both managements and employees should conform to this.

\section{Conclusions}

In conclusion, this paper makes two main contributions. On the one hand, Deontology is a basic ethical theory in business and one of the standards to judge whether a business operating ethically or not. This paper evaluates Takata's actions do not meet the ethical standards in Deontology, so they did not op- 
erate ethically. Furthermore, Takata should be mostly blamed for this case. On the other hand, there are recommendations for ethical business practices based on Deontology. Each person should obey three principles of Categorical Imperatives. They could institute a "Whistle Blowing Policy" to encourage people to speak up and protect them at the same time from retaliations. One is to design a better reporting system in the specific industry. Another one is to reinforce the responsible law to be held responsible to individuals.

Although the bankruptcy of Takata is coming, the event of Takata gives a warning to other auto manufacturers. They should focus on the inspection of airbag products and might have stricter standards to produce and test items. Fraud is a behaviour against Deontology. If companies act in this way, they will be revealed and blamed in the end. Therefore, Deontology is significant for the ethical business operating.

\section{Acknowledgements}

The author thanks Mr. Marcos Tabacow for his valuable comments and helpful suggestions on the first version of this paper.

\section{Conflicts of Interest}

The author declares no conflicts of interest regarding the publication of this paper.

\section{References}

[1] Ammons, R. (2015) The Deadly Impact of Exploding Air Bags. Trial, 51, 16.

[2] Wright, R. (2014) Carmakers Blame Takata for Slow Airbag Recall. Financial Times, 14.

[3] Anonymous (2017) Takata Agrees to \$1 Billion Airbag Settlement. Risk Management, 64, 25.

[4] Gaskill, T. (2016) A ticking Time Bomb. Quality Progress, 49, 10-11, 13.

[5] Jordan, T. and Mehta, P. (2017) Q\&A: Expert Answers. Quality Progress, 50, 12-13.

[6] Micewski, E. and Troy, C. (2007) Business Ethics-Deontologically Revisited. Journal of Business Ethics, 72, 17-25. https://doi.org/10.1007/s10551-006-9152-Z

[7] Wood, A.W. (2008) Kantian Ethics. Cambridge University Press, New York.

[8] Yang, X. (2006) Categorical Imperatives, Moral Requirements, and Moral Motivation. Metaphilosophy, 37, 112-129. https://doi.org/10.1111/j.1467-9973.2006.00419.x

[9] Nelson, J. (2017) The Corruption Norm. Journal of Management Inquiry, 26, 280-286. https://doi.org/10.1177/1056492616675415

[10] Skakoon, J.G. (2016) Ethics Revisited. Mechanical Engineering, 138, 16.

[11] Vadastreanu, A.M., Maier, D. and Maier, A. (2015) Is the Success Possible in Compliance with Ethics and Deontology in Business? Procedia Economics and Finance, 26, 1068-1073. https://doi.org/10.1016/S2212-5671(15)00931-4 